\title{
A New Approach for the Characterization of Organic Residues from Stone Tools Using GC $\times$ GC-TOFMS
}

\author{
Katelynn A. Perrault ${ }^{1, *}$, Pierre-Hugues Stefanuto ${ }^{1}$, Lena Dubois ${ }^{1}$, Dries Cnuts ${ }^{2}$, Veerle Rots ${ }^{2}$ \\ and Jean-François Focant ${ }^{1}$ \\ 1 Organic and Biological Analytical Chemistry Group, Chemistry Department, University of Liège, Allée du 6 \\ Août 11 (Bât B6c), Quartier Agora, Sart-Tilman, Liège 4000, Belgium; phstefanuto@ulg.ac.be (P.-H.S.); \\ lena.dubois@doct.ulg.ac.be (L.D.); jf.focant@ulg.ac.be (J.-F.F.) \\ 2 Traceolab/Prehistory, University of Liège, Quai Roosevelt 1B (Bât. A4), Liège 4000, Belgium; \\ dries.cnuts@ulg.ac.be (D.C.); veerle.rots@ulg.ac.be (V.R.) \\ * Correspondence: katelynn.perrault@ulg.ac.be; Tel.: +32-4-366-3430; Fax: +32-4-366-4387 \\ Academic Editor: Shari Forbes \\ Received: 23 March 2016; Accepted: 13 May 2016; Published: 18 May 2016
}

\begin{abstract}
Headspace solid-phase microextraction (HS-SPME) and gas chromatography-mass spectrometry (GC-MS) have traditionally been used, in combination with other analyses, for the chemical characterization of organic residues recovered from archaeological specimens. Recently in many life science fields, comprehensive two-dimensional gas chromatography-time-of-flight mass spectrometry (GC $\times$ GC-TOFMS) has provided numerous benefits over GC-MS. This study represents the first use of HS-SPME-GC $\times$ GC-TOFMS to characterize specimens from an experimental modern reference collection. Solvent extractions and direct analyses were performed on materials such as ivory, bone, antlers, animal tissue, human tissue, sediment, and resin. Thicker film column sets were preferred due to reduced column overloading. The samples analyzed by HS-SPME directly on a specimen appeared to give unique signatures and generally produced a higher response than for the solvent-extracted residues. A non-destructive screening approach of specimens may, therefore, be possible. Resin and beeswax mixtures prepared by heating for different lengths of time appeared to provide distinctly different volatile signatures, suggesting that GC $\times$ GC-TOFMS may be capable of differentiating alterations to resin in future studies. Further development of GC $\times$ GC-TOFMS methods for archaeological applications will provide a valuable tool to uncover significant information on prehistoric technological changes and cultural behavior.
\end{abstract}

Keywords: HS-SPME; GC $\times$ GC-TOFMS; volatile signature; archaeology; organic residues

\section{Introduction}

Gas chromatography coupled to mass spectrometry (GC-MS), in combination with non-contact sampling methods such as headspace solid-phase microextraction (HS-SPME), is a popular technique used in archaeological research for organic residue analyses [1-5]. This is a particularly challenging area of research for several reasons. First and probably most pertinent, the amount of organic residue available for analysis is most often extremely minimal. In addition, the age of archaeological specimens typically results in some or extensive degradation. To complicate the situation further, the detailed environmental history of the sample and potential exposure to contamination is unknown. Finally, an ideal method of analysis should be non-destructive in order to preserve the sample if other testing is required. Despite being a particularly challenging area of research, GC-MS has been employed successfully in numerous archaeological investigations including, but not limited to, the analysis of smoking pipe residue from ancient burials [6], ceramics [7], plasters [7], resins [2,5,8-10], and resin additives, such as beeswax $[9,11]$. 
Many of the matrices suggested above are also challenging to analyze because they are comprised of a complex range of non-volatile, semi-volatile, and volatile components [2,5]. The history of the sample only adds to this complexity, leading to the degradation of certain components and the potential for contaminant compounds to become present over time. A number of studies using one-dimensional gas chromatography (1D GC) have demonstrated the complexity of a vast range of modern reference and archaeological samples $[1,3,9,12-14]$. In these studies, total ion current (TIC) chromatograms typically exhibit a large number of compounds with a broad dynamic range, and therefore may suffer from insufficient baseline separation of compounds. This could potentially lead to peaks that are obscured by co-elutions and, therefore, are not detected, or potentially peak misidentification using mass spectrometry. Derivatization is often used to reduce matrix effects $[2,5,9]$; however, many TIC chromatograms in published literature still exhibit poor baseline separation likely due to co-elution with an unresolved complex mixture (UCM) coming from the matrix. Co-elution of peaks at the detector can result in poor mass spectral library matches, which may result in the lack of an identity assigned to a peak, or in a more unfortunate scenario, may cause peak misidentification. The large number of trace components and UCM present in these chromatograms can also obscure baseline separation of components which may result in non-optimal quantification, especially in the absence of robust deconvolution algorithms. This can potentially impact age estimations when investigating degradation markers.

It is proposed that characterization of archaeological samples would benefit substantially from the use of comprehensive two-dimensional gas chromatography-time-of-flight mass spectrometry (GC $\times$ GC-TOFMS). This comprehensive, multidimensional technique offers an improved peak capacity, leading to considerable enhancement in peak separation and subsequent quantification. GC $\times$ GC is similar to 1D GC in most principles; however, it exploits the use of both a first dimension $\left({ }^{1} \mathrm{D}\right)$ and second dimension $\left({ }^{2} \mathrm{D}\right)$ column to produce two independent mechanisms of separation. The 1D separation is comparable to a conventional 1D GC run. Short plugs of eluent from the ${ }^{1} \mathrm{D}$ column are trapped, focused, and released at the modulator. These small plugs of eluent are then injected onto the shorter ${ }^{2} \mathrm{D}$ column that exhibits a different stationary phase, where they undergo a secondary separation. This generates a chromatogram based on both a first dimension retention time $\left({ }^{1} t_{R}\right)$ and second dimension retention time $\left({ }^{2} t_{\mathrm{R}}\right)$. The resulting two-dimensional plane creates a drastic increase in the number of compounds that can be separated, hence improving the overall peak capacity of the system. GC $\times$ GC additionally offers the advantage of global method sensitivity enhancement following cryogenic zone compression (CZC) [15]. The output based on three axes $\left({ }^{1} t_{R},{ }^{2} t_{R}\right.$, and intensity) improves the visualization of the characteristics of complex samples, therefore presenting an attractive option for end users in various life science application areas [16]. This is further enhanced by the availability of a fourth mass spectral axis that provides information about the identity of the chromatographic signals through the use of deconvoluted TOFMS fragmentation spectra that can be compared to reference spectral libraries.

Overall, this technique is highly sensitive and selective and has been shown to be extremely successful in other fields of VOC measurements such as forensic taphonomy [16-20], arson investigation [21], breath analysis [22], food and fragrance analysis [23,24], and many others. However, in most of these applications, the quantity of the sample is higher and the age of the sample is much more recent when comparing with archaeological investigations. Therefore, the aim of this proof-of-concept study was to screen several types of modern reference specimens with a generic volatile method using HS-SPME-GC $\times$ GC-TOFMS to determine whether valuable results could be obtained with the types and amount of sample typically available. This was done with the aim of presenting insights into the use of GC $\times$ GC-TOFMS in the future of archaeological research. 


\section{Materials and Methods}

\subsection{Samples}

A wide range of samples available in an experimental reference collection were tested (Table 1). These samples were chosen based on availability and based on the types of samples and materials typically encountered during an archaeological recovery. Residues were from modern samples which were either collected directly (i.e., from plants or animals) or were collected from experimental stone tools. The former were immediately placed in vials for analysis. The latter were derived from modern reproductions of archaeological stone tools, which were used in modern settings for a range of activities relevant for prehistoric lifeways (e.g., hunting, butchering, hideworking, etc.).

Table 1. Preparation of sample vials containing organic residue prior to SPME sampling.

\begin{tabular}{|c|c|c|}
\hline Sample Name & Mode of Preparation & Approximate Age (If Known) \\
\hline Ivory (dry) & Water extraction & 3 years \\
\hline Ivory powder & Manually placed in vial & \\
\hline Bone (dry) & Water extraction & 3 years \\
\hline Bone powder & Manually placed in vial & \\
\hline Sediment \& bone powder & $\begin{array}{c}\text { Mixture of sediment and powder manually } \\
\text { placed in vial }\end{array}$ & \\
\hline Meat \& starch & Water extraction & \\
\hline Meat \& starch & Water extraction/ultrasonic bath & \\
\hline Meat, blood \& fat & Water extraction & \\
\hline Meat, blood \& fat & Solvent extraction & \\
\hline Sample name & Mode of preparation & Approximate age (if known) \\
\hline Hide (fresh) & Water extraction & 4 months frozen \\
\hline Hide (fresh) & Solvent extraction & 4 months frozen \\
\hline Hide (fresh) & Piece manually placed in tube & 4 months frozen \\
\hline Hand residue $^{1}$ & Water extraction & \\
\hline Hand residue & Solvent extraction & \\
\hline Resin $^{2} \&$ beeswax ${ }^{3}$ mixture & $\begin{array}{l}\text { 1:1 mixture prepared by heating until liquid } \\
\text { and mixing together, } 2 \mathrm{~g} \text { of final mixture } \\
\text { was manually placed in vial }\end{array}$ & \\
\hline $\begin{array}{l}\text { Resin \& beeswax mixture } \\
\text { (Heated } 1 \mathrm{~h})\end{array}$ & $\begin{array}{l}\text { Prepared as above but heated for an } \\
\text { additional } 1 \mathrm{~h} \text { after mixing }\end{array}$ & \\
\hline Plastiline ${ }^{4}$ & Water extraction & \\
\hline Antler & Water extraction & \\
\hline Leather from binding & Water extraction & \\
\hline Sediment & Water extraction/ultrasonic bath & 33,000 years \\
\hline Blank vial & $\mathrm{N} / \mathrm{A}$ & \\
\hline
\end{tabular}

${ }^{1}$ Hand residue: A stone tool was handled by the researcher without gloves and an extraction was taken afterwards; ${ }^{2}$ Picea abies resin, Natural, Rochefort, Belgium; ${ }^{3}$ Beeswax, Natural, Rochefort Belgium; ${ }^{4}$ Plastiline, J Herbin, Paris France.

In order to extract the residues from these stone tools, two types of commonly used extraction techniques $[25,26]$ were investigated. Water extraction was performed by pipetting $4 \mu \mathrm{L}$ of distilled water onto the surface of the item, agitating the liquid with the pipette tip, and then reaspirating the water into a headspace vial. Solvent extraction was also performed in the same manner but using a mixture of ethanol (VWR collection, Fontenay-sous-Bois, France), distilled water (Delhaize, Liège, Belgium), and acetonitrile (Merck Millipore, Darmstadt, Germany) in a 1:1:1 ratio. Pipetting was performed with a Transferpette ${ }^{\circledR} S$ (VWR International, Leuven, Belgium) with polypropylene tips. Water extraction with ultrasonication was also performed on some samples which involved placing the material in a weigh boat with $5 \mathrm{~mL}$ of distilled water and performing ultrasonication (Elmasonic $\mathrm{P}$ $120 \mathrm{H}$, Elma, Singen, Germany) for $5 \mathrm{~min}$ at $37 \mathrm{kHz}$, after which the liquid and material were poured into a headspace vial. A full description of extractions and treatments performed to prepare sample vials is shown in Table 1. All samples were prepared in $20 \mathrm{~mL}$ screw cap headspace vials with $1.3 \mathrm{~mm}$ PTFE septa $\left(\right.$ Gerstel $^{\circledR}$, Kortrijk, Belgium). 
Although the residues were from modern references, a sediment sample on an ancient stone tool was also analyzed. This sample was derived from a stone tool found in a stratified cave site in a layer dated to approximately 33,000 years ago. This situation is important in an archaeological context in order to determine whether it is possible to differentiate between a general taphonomic signature (e.g., the sediment) and the unique signature of use-related residues on the tool itself. Although additional studies need to be performed to answer this question in its entirety, this sample was analyzed in order to incorporate a particular situation in which GC $\times$ GC-TOFMS may be useful for providing information to differentiate two volatile signatures.

\subsection{Instrumental Analysis}

Samples were analyzed using a Pegasus 4D GC $\times$ GC-TOFMS $\left(\right.$ LECO $^{\circledR}$ Corporation, St. Joseph, MI, USA) equipped with a secondary oven and a quad-jet, dual-stage, thermal modulator. The ${ }^{1} \mathrm{D}$ column was an Rtx-5MS (Restek ${ }^{\circledR}$ Corporation, Bellefonte, PA, USA) $(30 \mathrm{~m} \times 0.25 \mathrm{~mm}$ i.d. $\times 0.25 \mu \mathrm{m} \mathrm{d}$ ), and the ${ }^{2} \mathrm{D}$ column was an Rxi-17Sil MS (Restek ${ }^{\circledR}$ Corporation) $\left(1.0 \mathrm{~m} \times 0.15 \mathrm{~mm}\right.$ i.d. $\times 0.15 \mu \mathrm{m} \mathrm{d}_{\mathrm{f}}$ ). The connection between the two columns was performed used a SilTite $\mu$-union (SGE Analytical Science ${ }^{\circledR}$, Wetherill Park, Australia). All samples were run on this column set with settings described in the following paragraphs, but selected samples were further investigated on two other column sets: Rxi-624Sil MS ${ }^{1} \mathrm{D}$ column (Restek ${ }^{\circledR}$ Corporation) $\left(30 \mathrm{~m} \times 0.25 \mathrm{~mm}\right.$ i.d. $\left.\times 1.40 \mu \mathrm{m} \mathrm{d}_{\mathrm{f}}\right) \times$ Stabilwax ${ }^{2} \mathrm{D}$ column (Restek ${ }^{\circledR}$ Corporation) $\left(2 \mathrm{~m} \times 0.25 \mathrm{~mm}\right.$ i.d. $\left.\times 0.50 \mu \mathrm{m} \mathrm{d}_{\mathrm{f}}\right)$; Stabilwax ${ }^{1} \mathrm{D}$ column $(25 \mathrm{~m} \times$ $0.25 \mathrm{~mm}$ i.d. $\left.\times 0.50 \mathrm{~d}_{\mathrm{f}}\right) \times$ Rtx-200Sil MS ${ }^{2} \mathrm{D}$ column (Restek ${ }^{\circledR}$ Corporation) $\left(1 \mathrm{~m} \times 0.25 \mathrm{~mm}\right.$ id $\left.\times 0.25 \mathrm{~d}_{\mathrm{f}}\right)$.

The sample vials were extracted using automated HS-SPME with a multipurpose sampler (MPS) $\left(\right.$ Gerstel ${ }^{\circledR}$ ). A 50/30 $\mu$ m divinylbenzene/carboxen/polydimethylsiloxane (DVB/CAR/PDMS) Stableflex $24 \mathrm{Ga}$ fiber was chosen (Supelco ${ }^{\circledR}$, Bellefonte, PA, USA) based on previous literature [5] and experience characterizing similar types of expected volatiles. Each vial was first incubated at $50{ }^{\circ} \mathrm{C}$ for $10 \mathrm{~min}$. The fiber was exposed for $15 \mathrm{~min}$ to the headspace of each sample with a penetration depth of $21.00 \mathrm{~mm}$. The fiber was desorbed with a penetration depth of $54.00 \mathrm{~mm}$ for $180 \mathrm{~s}$ in a CIS4 Cooled Injection System $\left(\right.$ Gerstel $\left.{ }^{\circledR}\right)$. The injector temperature was programmed at $-10{ }^{\circ} \mathrm{C}$ for $0.15 \mathrm{~min}$, was increased to $350{ }^{\circ} \mathrm{C}$ at $12.00^{\circ} \mathrm{C} \cdot \mathrm{s}^{-1}$, and then held at $350{ }^{\circ} \mathrm{C}$ for $5.00 \mathrm{~min}$. The injection was performed in splitless mode with a $3 \mathrm{~mL} \cdot \mathrm{min}^{-1}$ septum purge flow and a purge time of $120 \mathrm{~s}$. The inlet purge flow was $20 \mathrm{~mL} \cdot \mathrm{min}^{-1}$.

High purity helium (Air Liquide ${ }^{\circledR}$, Liège, Belgium) carrier gas flow was held at a constant rate of $1.00 \mathrm{~mL} \cdot \mathrm{min}^{-1}$ throughout the run. The ${ }^{1} \mathrm{D}$ oven was held initially at $50{ }^{\circ} \mathrm{C}$ for $3 \mathrm{~min}$, followed by an increase to $220^{\circ} \mathrm{C}$ at a rate of $5^{\circ} \mathrm{C} \cdot \mathrm{min}^{-1}$ (total $37 \mathrm{~min}$ ). The ${ }^{2} \mathrm{D}$ oven offset was $+15^{\circ} \mathrm{C}$ above the ${ }^{1} \mathrm{D}$ oven temperature and the modulator offset was $+20^{\circ} \mathrm{C}$ from the ${ }^{2} \mathrm{D}$ oven. A 3 s modulation period $\left(P_{\mathrm{M}}\right)$ was used with a $0.40 \mathrm{~s}$ hot pulse time. An acquisition delay of $300 \mathrm{~s}$ was used. The MS transfer line was held at $220^{\circ} \mathrm{C}$. The mass acquisition range was $29-450 \mathrm{amu}$ and operated with a rate of $100 \mathrm{~Hz}$. The ion source temperature was $230^{\circ} \mathrm{C}$ and the electron ionization energy was $70 \mathrm{eV}$. The detector voltage was $1500 \mathrm{~V}$.

\subsection{Data Processing}

As the objective of this proof-of-concept study was to screen various sample types, tentative compound identifications were performed based on the National Institute of Standards and Technology (NIST) 2014 and Wiley 10 libraries with a match factor threshold > 700. Peaks identified below this threshold were labelled "unknown" and those above this threshold were labelled with tentative names. Sample acquisition and peak finding was performed using ChromaTOF v. 4.50.8.0 (LECO ${ }^{\circledR}$ Corporation). A baseline offset of 0.6 was used, with a $12 \mathrm{~s}^{1} \mathrm{D}$ peak width and a $0.1 \mathrm{~s}{ }^{2} \mathrm{D}$ peak width. A signal-to-noise $(S / N)$ ratio of 50 was used and unique mass was used for area calculations. Statistical Compare was used by importing the samples into two classes (i.e., blanks and samples) in order to perform peak alignment and filtering of non-specific peaks (e.g., column bleed, background compounds, etc.). The analyte spectral match required a mass threshold of 10 and a minimum similarity 
match of 600. Peaks were searched for a second time if not identified by the initial peak find algorithm down to a $S / N$ of 20. A Fisher Ratio (FR) was calculated for each compound and compounds with undefined FRs (i.e., only present in one class) or those exceeding the calculated critical F-value $\left(F_{\text {crit }}\right)$ (i.e., present in both classes but highly variable) were kept for further processing. This approach has already been well-established in several volatile profiling studies [27-29].

\section{Results and Discussions}

\subsection{Chromatographic Considerations and Sample Analysis}

Data processing revealed anywhere from 200 to 2000 features identified within a sample. Figure 1 shows a variety of chromatograms obtained using the Rtx-5MS $\times$ Rxi-17Sil MS column set. The resin samples yielded the most complex volatile signature of all sample types analyzed. Resin is an important substance in archaeological research as it has been used during prehistory as an adhesive to haft stone tools $[9,30]$. Hafting is considered an invention that revolutionized stone tool use [30,31] and that necessitated abstract thought and planning $[9,32]$. Therefore, being able to understand the mode of preparation allows an understanding of the cognitive and technical capabilities of their makers [33]. Figure 1 (top left and top right) demonstrates the ability to differentiate the volatile signature of the two resin and beeswax mixture samples based on different preparation methods differentiated by heating length. It, therefore, follows that it may be possible, given a larger database of controlled study information, to provide more information in the future about the type of resin discovered on an archaeological tool and its potential mode of preparation.
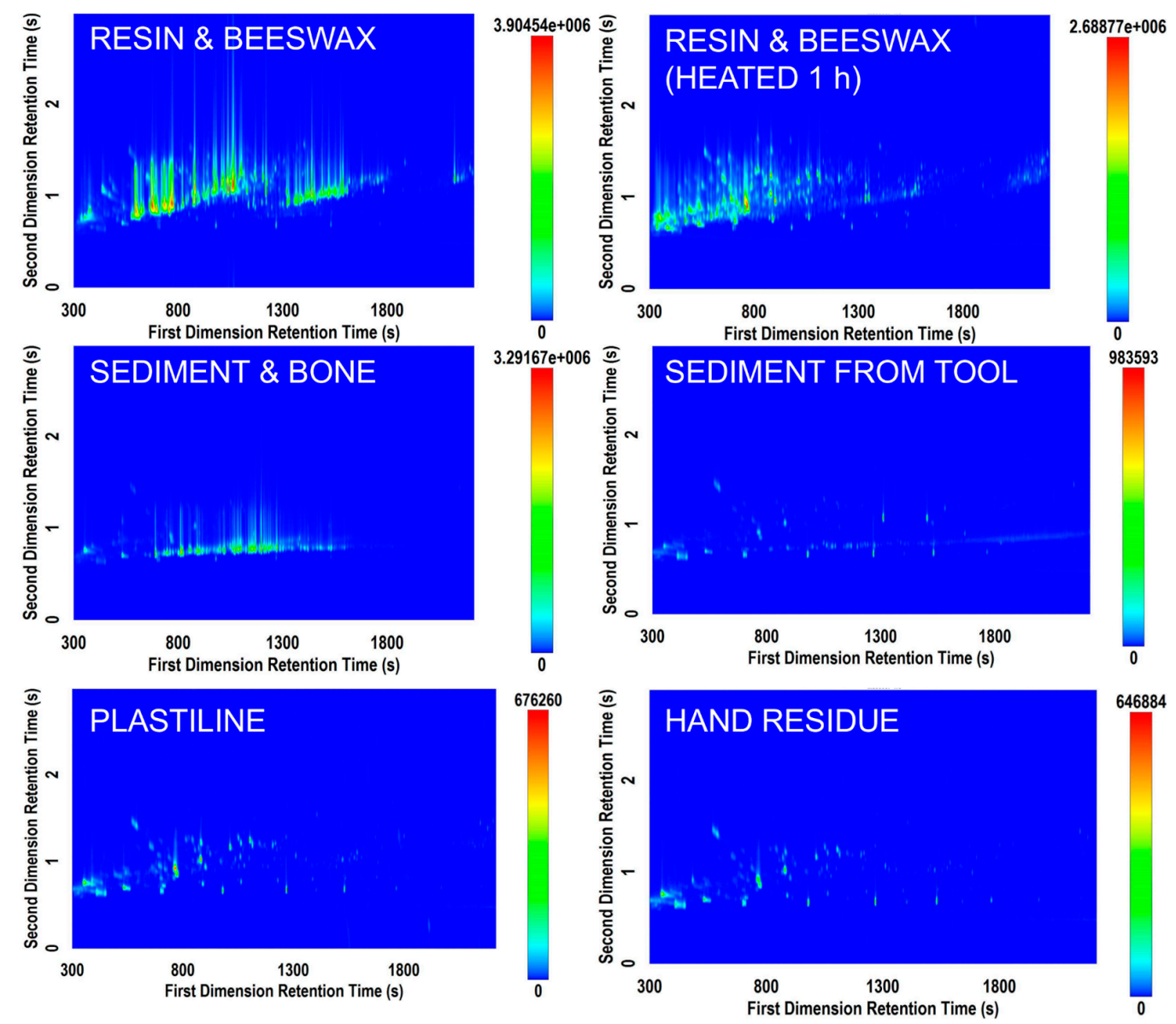

Figure 1. Selected total ion current (TIC) contour plots from six samples analyzed on the Rtx-5MS × Rxi-17Sil MS column set. 
The sample of mixed sediment and bone displayed in Figure 1 also yielded a complex profile (middle left). This sample exhibited numerous hydrocarbon compounds, leading to a need for more effective optimization of the first dimension separation. There were only few trace compounds that eluted separately along the second dimension axis, suggesting that a well-optimized 1D GC-MS method may be useful in screening sediment samples if bone fragments are suspected to be contained in them (i.e., differentiation of sediment from sediment mixed with bone). However, this GC $\times$ GC-TOFMS method had added value in providing a "total screening" approach, in that the same method could potentially be applied to a vast array of potential unknown residues to provide information about sample characteristics. In an archaeological context, due to the minimal amounts of samples available it may not be possible to distinguish visually (or microscopically) between a sediment sample and other possible organic residues. A total screening approach can be valuable from an investigative standpoint and when processing a large number of samples from an archaeological site. In addition, comparing results from sediment samples and extractions from stone tools can help in distinguishing between residues that can be linked to the use of a specific stone tool and residues that occur on a more general level throughout the site. The signature from a minimal amount of sediment washed from an archeological stone tool also yielded a volatile signature different than that from the mixed sediment and bone sample. In this situation, the number of components in the volatile signature was fewer but there was a higher need for the selectivity of GC $\times$ GC-TOFMS due to the fact that more compounds separated along the ${ }^{2} \mathrm{D}$ axis.

The samples of ivory, bone, meat/starch, antler, meat/starch/blood, and leather generated minimal signals that could not be visually differentiated from blank vials without further testing. This could be due to the fact that no volatile compounds existed in the samples that were available for SPME extraction. It could also be due to the fact that a longer or warmer SPME extraction was required to release characteristic volatiles from these matrices. In addition, obtaining experimental replicates would allow for the generation of statistics that could assist in determining whether a peak is discriminatory for that sample type, and therefore would lead to more robust determinations of compound importance. Although strong GC $\times$ GC-TOFMS signals were not obtained for these samples, further analytical optimization may prove valuable in the future for their characterization.

Figure 2 shows the fresh resin and beeswax mix characterized on the three different column sets. Each column set yielded a slightly different structure of chromatogram. The first column set (top) is a non-polar $\times$ polar column combination, which is a conventional column set used for initial testing. The middle chromatogram demonstrates a mid-polar $\times$ polar column combination, and the bottom chromatogram demonstrates a polar $\times$ mid-polar combination. The groupings of terpenes and terpenoids appear at different angles depending on the column set. The best separation was obtained by the Rtx-624Sil MS $\times$ Stabilwax column set in this study. However it is suspected that optimization of conditions could potentially lead to sufficient separation over the chromatographic space using any one of these phase combinations. 

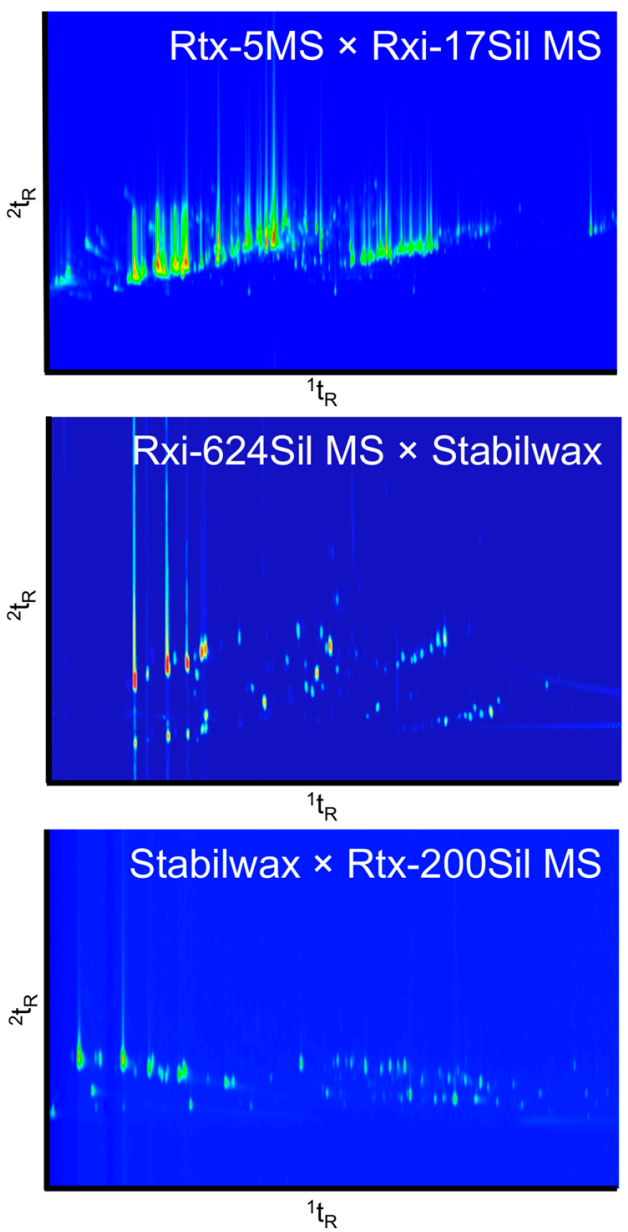

Figure 2. Column set comparison of a resin and beeswax (1:1) mixture analyzed on three different column sets. Top: Rtx-5MS (30 $\mathrm{m} \times 0.25 \mu \mathrm{m}$ i.d. $\left.\times 0.25 \mathrm{~d}_{\mathrm{f}}\right) \times$ Rxi-17Sil MS $\left(1 \mathrm{~m} \times 0.15 \mu \mathrm{m}\right.$ i.d. $\left.\times 0.15 \mathrm{~d}_{\mathrm{f}}\right)$, $P_{\mathrm{M}}=3 \mathrm{~s}$; Middle: Rxi-624Sil MS (30 m $\times 0.25 \mu \mathrm{m}$ i.d. $\left.\times 1.4 \mathrm{~d}_{\mathrm{f}}\right) \times$ Stabilwax $\left(2 \mathrm{~m} \times 0.25 \mu \mathrm{m}\right.$ i.d. $\left.\times 0.5 \mathrm{~d}_{\mathrm{f}}\right)$, $P_{\mathrm{M}}=4$ s; Bottom: Stabilwax $\left(25 \mathrm{~m} \times 0.25 \mu \mathrm{m}\right.$ i.d. $\left.\times 0.5 \mathrm{~d}_{\mathrm{f}}\right) \times$ Rtx-200Sil MS $\left(1 \mathrm{~m} \times 0.25 \mu \mathrm{m}\right.$ i.d. $\left.\times 0.25 \mathrm{~d}_{\mathrm{f}}\right)$ $P_{\mathrm{M}}=2 \mathrm{~s}$.

Using the first column set, there was a large amount of peak tailing in both the ${ }^{1} \mathrm{D}$ and ${ }^{2} \mathrm{D}$. This phenomenon was attributed to the thinner films used for the columns in the Rtx-5MS $\times$ Rxi-17Sil MS set in comparison to the other column sets tested. Second dimension tailing was apparent for many of the samples, as seen in Figure 1. However, some samples also exhibited peak tailing in the ${ }^{1} \mathrm{D}$ which led to exaggerated " $\mathrm{L}$ "-shaped peaks. This was most apparent for samples that contained carboxylic acids, such as the hide sample displayed in Figure 3. Increasing the film thickness of the columns increased the retention time of specific compounds, yet allowed for improved resolution of the volatile compounds being analyzed. The third column combination, Stabilwax $\times$ Rtx-200Sil MS, had reduced peak tailing in the ${ }^{1} \mathrm{D}$ due to the thicker film on this column, but continued to exhibit considerable peak tailing in the ${ }^{2} \mathrm{D}$ due to the thin film on the Rtx-200Sil MS column.

On the first column set with thin film thicknesses in both dimensions, some compounds tailed across the majority of the ${ }^{2} \mathrm{D}$, which is not ideal in a GC $\times \mathrm{GC}$ analysis where the ${ }^{2} \mathrm{D}$ should be used as an additional dimension of selectivity. Nonetheless, due to the preliminary nature of this work, this column set was used for initial analysis of all samples as it was considered to be the conventional column set and would, therefore, provide a potential starting point for comparison to the literature. However, future analyses will likely be performed using the Rxi-624Sil MS $\times$ Stabilwax column set due to the improved peak shape and resolution for the type of compounds being analyzed. 
Figure 3 also demonstrates the complexity of the volatile signature of these samples. The red insert displays the dynamic range of compounds and potential for co-elution in the first dimension. These issues are mitigated using GC $\times$ GC whereby the selectivity of the secondary phase affords improved peak capacity for separating trace compounds from high abundance compounds. Selected compounds labelled in Figure 3 demonstrates the wide range of potential compounds that can be encountered when examining volatiles from mammalian tissues. The ability to fully characterize the complexity of these types of matrices, even in trace quantities, will be extremely beneficial to improve the characterization of volatiles from archaeological residues.

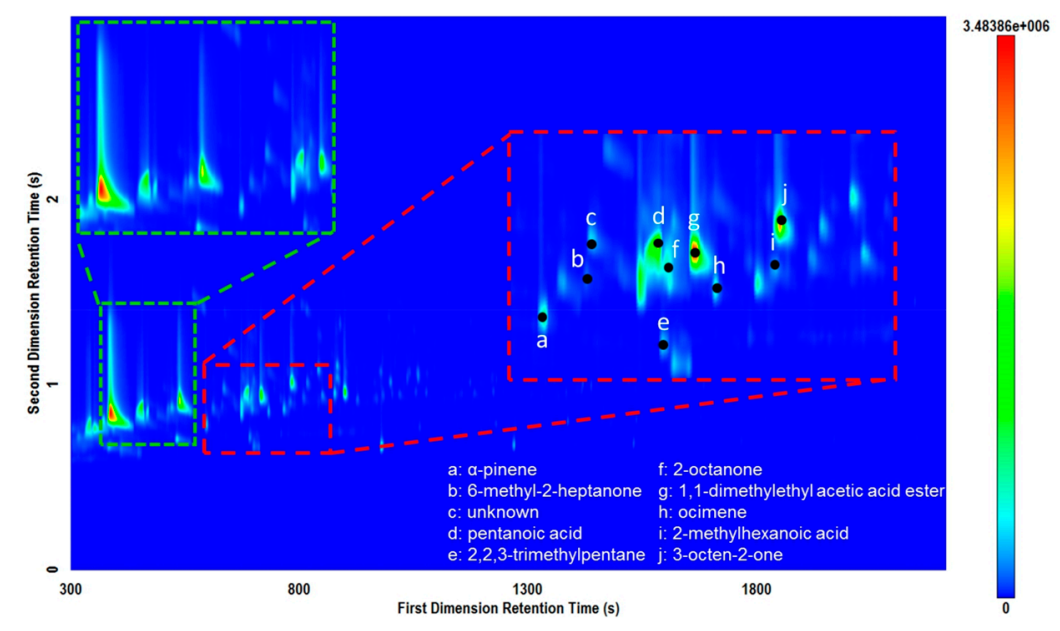

Figure 3. Total ion current (TIC) contour plot for a piece of hide sample analyzed on the Rtx-5MS $\times$ Rxi-17Sil MS column set demonstrating "L"-shaped peaks for some carboxylic acid peaks (green). Several labeled peaks demonstrate the value of the GC $\times$ GC selectivity and typical compounds obtained (red).

\subsection{Sample Extraction Techniques}

Figure 4 displays the comparison of different potential methods of extracting volatiles for analysis from animal hide. Based on the results of this study, improved results (i.e., richer chromatograms) were generally obtained when the HS-SPME extraction was performed directly on the residue of interest rather than on an extract from an item. However, due to the common practice of performing solvent extractions from items of interest in archaeological research, both approaches were tested. Further studies with sample replication may demonstrate the potential effects of different solvents or ultrasonication to optimize extraction of specific residues and provide additional comparison to performing direct analysis of residue.

Previous studies of archaeological residues have typically relied on extraction and derivitization $[5,9,10]$. However, the development of a non-destructive direct HS-SPME extraction from the residue is a substantial benefit, as further analyses can then be conducted on the item in its original state after it has been screened by VOC analysis. This requires no solvents or derivatization agents and less physical handling of potentially important items and residues. It is currently unknown what amount of material is necessary in order to detect the volatile signature directly from various samples by GC $\times$ GC-TOFMS. For example, the volume of blood, mass of resin, and/or mass of sediment collected may be too low to produce a sufficiently concentrated headspace for analysis. In addition, residues may be a combination of several traces. For example, this could occur if a stone tool was used to cut both vegetal material and a piece of meat. At trace levels, it is unknown how these volatiles signatures may interact and whether this technique would be capable of differentiating such minimal traces. 


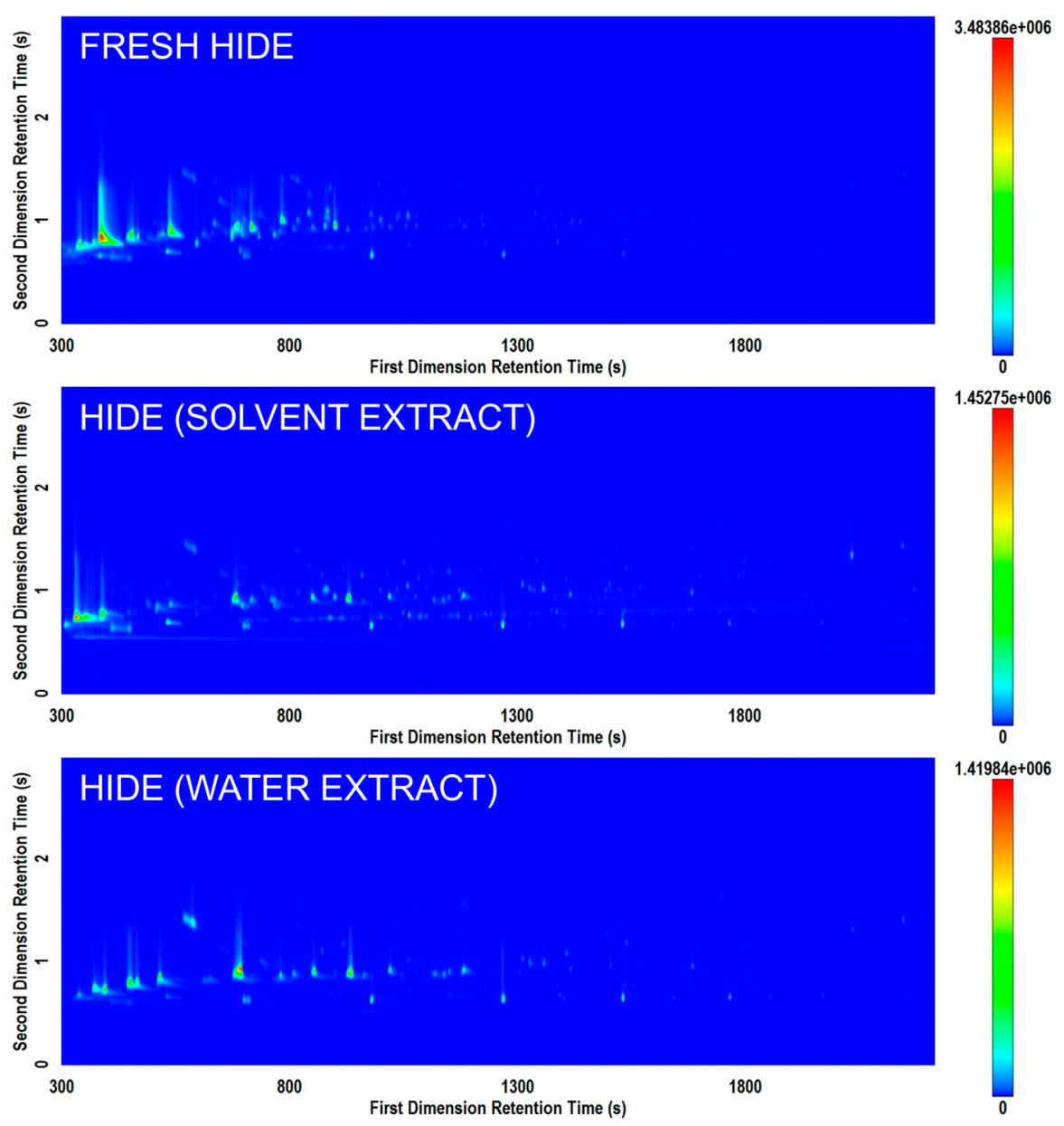

Figure 4. Comparison of total ion current (TIC) contour plots for three hide samples prepared by direct analysis (top); extraction in a mixture of solvents (middle); and extraction in water (bottom) on the Rtx-5MS $\times$ Rxi-17Sil MS column set.

\subsection{Interferences}

Due to the trace nature of this type of profiling, it was necessary to include samples that would allow the assessment of potential contamination or interferences with the ability to successfully obtain a volatile signature. Two samples were included in the analysis which allowed an initial assessment of such a situation.

Plastiline, an oil-based modelling clay used for mounting artefacts for microscopic analysis, was extracted and the extraction liquid was placed in a vial. Plastiline is a proprietary product whose composition is protected by patents. It generally contains oils, waxes, clay minerals, and in some cases a small portion of sulfur [34]. This is important in determining the workflow for a particular archaeological item of interest. In the situation where plastiline (or other mounting product) generates an interfering signal, the volatile signature may possibly be overwhelmed by plastiline volatiles and be unidentifiable.

The plastiline was found to contain minimal but identifiable levels of some volatiles such as hydrocarbons, aldehydes, ethers, ketones, and aromatics. No sulfur compounds were detected in the volatile profile, indicating that the ingredients of this particular brand likely did not include any sulfur additives. Based on this initial analysis, plastiline could potentially provide an interference with volatile signatures of interest, especially when sample residues are present in trace quantities. In fact, many archaeological workflows no longer include this material due to the fact that it can cause damage to the physical appearance and chemical composition of the residues on a stone tool under examination [34]. 
This may also be the case for the volatile signature being created by the item of interest. This type of background signal, if known to be present during the workflow of an archaeological investigation, could be subtracted from the signal of the residue being analyzed. The nature of the GC $\times$ GC selectivity also reduces the risk that compounds of interest will co-elute with interfering compounds such as those found in plastiline. Future work may therefore require a comparison of different compositions of mounting materials, the method of application to archaeological artefacts, and the interference of these. This is less of an issue for more recent archaeological excavations, in particular those that took into account the necessary precautions for residue analysis; however, for some older excavations these potential contaminations may occur.

Due to the fact that GC $\times$ GC-TOFMS is a very sensitive technique, it was also necessary to determine whether the handling of archaeological artefacts without gloves may also interfere with the volatile signature from specimens of interest. The hand residue sample was produced by handling a tool with bare hands and then washing the tool with solvent to see if a background signal from the handling appeared. In this case, only trace levels of volatiles were contributed to the profile in comparison with a blank vial (Figure 1). However, it is still recommended that gloves are worn when handling specimens prior to volatile profiling. It is possible that with the sensitivity of this technique may cause the detection of secondary transfer of contaminant residues and interfere with the volatile profile of the target residue.

\subsection{Future Perspectives}

This preliminary analysis of a range of modern reproductions of archaeological specimens indicates that the potential of GC $\times$ GC-TOFMS to provide value for organic residue characterization is promising. Even in the absence of a robust HS-SPME optimization, notable volatile signatures could be investigated between the sample types analyzed. This also provides a potential avenue for a non-destructive analysis of the unaltered residue upon initial discovery, without requiring solvent extraction and/or derivitization. Although marker compounds cannot be extrapolated from this sample set, the analyses presented herein allowed for an evaluation of the general use of GC $\times$ GC-TOFMS for organic residue characterization. Since the SPME-GC $\times$ GC-TOFMS analysis is non-destructive, it can provide an additional tool to be incorporated in the analytical workflow of residue characterization, in addition to the vast array of instrumentation currently used for these purposes.

There are a number of future avenues for this work to be further investigated. First and foremost, it would be valuable to begin analyzing replicate experimental samples to be able to apply robust statistical methods for the objective differentiation of residues. This must be done on lower quantities of residue in order to ensure the robustness of characterization strategies. Applying artificial aging of controlled experimental samples may also aid in improving characterization approaches in the future. In addition, the application of these techniques to additional archaeological specimens with complex histories would be interesting in order to determine if the experimental data can be extrapolated to real scenarios.

In addition, the detection of compounds in this study was performed by low-resolution TOFMS. This affords the ability to perform mass spectral library searching and produce matches above a certain quality. However, in order to improve these identification, high-resolution mass spectrometry will be employed in the future. Some of the samples analyzed in this study contained extremely complex profiles, such as the resin samples that contained hundreds of components likely originating from plant materials within the resin or other additives. Differentiating compounds of this nature by low-resolution mass spectrometry can be difficult due to similarities in their produced spectra. GC $\times$ GC coupled with high-resolution mass spectrometry has the potential to provide a higher degree of discrimination between these compounds and improve the identification confidence.

Acknowledgments: We wish to thank Restek ${ }^{\circledR}$ Corporation, Trajan ${ }^{\circledR}$ Scientific and Medical, and Supelco Sigma-Aldrich ${ }^{\circledR}$ for providing us with GC phases and various consumables. Christian Lepers is further acknowledged for 
his creation of the reference collection used in this study, and for providing the resin and beeswax mixtures. The research of K.A.P. is supported by Wallonie-Bruxelles International. The research of D.C. and V.R. is supported by the European Research Council under the European Union's Seventh Framework Programme (FP/2007-2013)/ERC Grant Agreement No. 312283.

Author Contributions: J.-F.F. and V.R. conceived and designed the experiments; K.A.P., P.-H.S., L.D. and D.C. performed the experiments; K.A.P., P.-H.S. and L.D. analyzed the data; J.-F.F. and V.R. contributed reagents/materials/analysis tools; K.P. wrote the paper and K.A.P., J.-F.F., V.R., P.-H.S, L.D. and D.C. contributed to preparation and revisions of the paper.

Conflicts of Interest: The authors declare no conflict of interest.

\section{Abbreviations}

The following abbreviations are used in this manuscript:

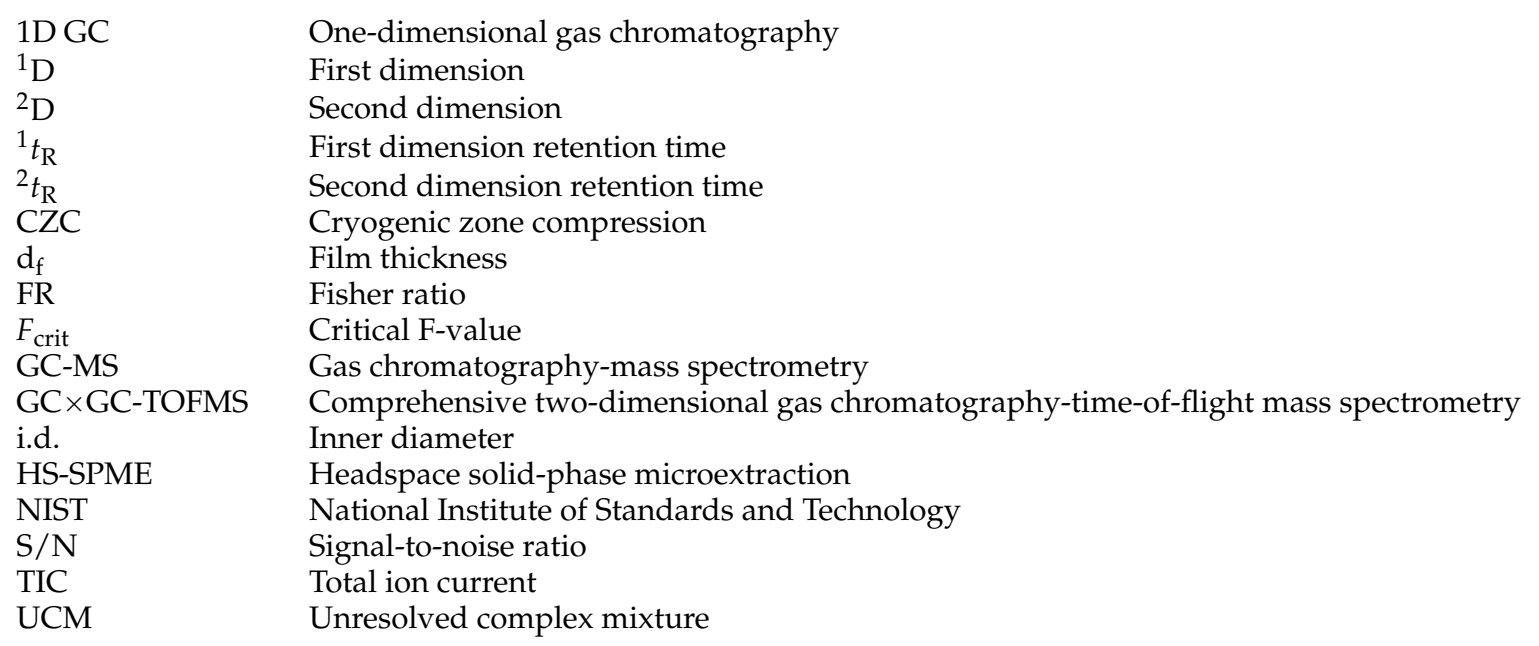

\section{References}

1. Hamm, S.; Bleton, J.; Connan, J.; Tchapla, A. A chemical investigation by headspace SPME and GC-MS of volatile and semi-volatile terpenes in various olibanum samples. Phytochemistry 2005, 66, 1499-1514. [CrossRef] [PubMed]

2. Hamm, S.; Lesellier, E.; Bleton, J.; Tchapla, A. Optimization of headspace solid phase microextraction for gas chromatography/mass spectrometry analysis of widely different volatility and polarity terpenoids in olibanum. J. Chromatogr. A 2003, 1018, 73-83. [CrossRef] [PubMed]

3. Jerković, I.; Marijanović, Z.; Gugić, M.; Roje, M. Chemical profile of the organic residue from ancient amphora found in the Adriatic Sea determined by direct GC and GC-MS analysis. Molecules 2011, 16, 7936-7948. [CrossRef] [PubMed]

4. Mcgovern, P.E.; Mirzoian, A.; Hall, G.R. Ancient egyption herbal wines. Proc. Natl. Acad. Sci. USA 2009, 106, 7361-7366. [CrossRef] [PubMed]

5. Regert, M.; Alexandre, V.; Thomas, N.; Lattuati-Derieux, A. Molecular characterisation of birch bark tar by headspace solid-phase microextraction gas chromatography-mass spectrometry: A new way for identifying archaeological glues. J. Chromatogr. A 2006, 1101, 245-253. [CrossRef] [PubMed]

6. Rafferty, S.M. Identification of Nicotine by Gas Chromatography/Mass Spectroscopy Analysis of Smoking Pipe Residue. J. Archaeol. Sci. 2002, 29, 897-907. [CrossRef]

7. Pecci, A.; Giorgi, G.; Salvini, L.; Ontiveros, M.Á.C. Identifying wine markers in ceramics and plasters using gas chromatography-mass spectrometry. Experimental and archaeological materials. J. Archaeol. Sci. 2013, 40, 109-115. [CrossRef]

8. Modugno, F.; Ribechini, E.; Colombini, M.P. Aromatic resin characterisation by gas chromatography-mass spectrometry. Raw and archaeological materials. J. Chromatogr. A 2006, 1134, 298-304. [CrossRef] [PubMed]

9. Regert, M. Investigating the history of prehistoric glues by gas chromatography-mass spectrometry. J. Sep. Sci. 2004, 27, 244-254. [CrossRef] [PubMed] 
10. Helwig, K.; Monahan, V.; Poulin, J.; Antiquity, A. The Identification of Hafting Adhesive on a Slotted Antler Point from a Southwest Yukon Ice Patch. Am. Anqituity 2014, 73, 279-288.

11. Regert, M.; Colinart, S.; Degrand, L.; Decavallas, O. Chemical alteration and use of beeswax through time: Accelerated ageing tests and analysis of archaeological samples from various environmental contexts. Archaeometry 2001, 43, 549-569. [CrossRef]

12. Mathe, C.; Culioli, G.; Archier, P.; Vieillescazes, C. Characterization of archaeological frankincense by gas chromatography-mass spectrometry. J. Chromatogr. A 2004, 1023, 277-285. [CrossRef] [PubMed]

13. Boëda, E.; Connan, J.; Dessort, D.; Muhesen, S.; Mercier, N.; Valladas, H.; Tisnérat, N. Bitumen as a hafting material on Middle Palaeolithic artefacts. Nature 1996, 380, 336-338. [CrossRef]

14. Evershed, R.P.; Heron, C.; Goad, J. Analysis of organic residues of archaeological origin by high-temperature gas chromatography and gas chromatography mass spectrometry. Analyst 1990, 115, 1339-1342. [CrossRef]

15. Patterson, D.G.; Welch, S.M.; Turner, W.E.; Sjödin, A.; Focant, J.F. Cryogenic zone compression for the measurement of dioxins in human serum by isotope dilution at the attogram level using modulated gas chromatography coupled to high resolution magnetic sector mass spectrometry. J. Chromatogr. A 2011, 1218, 3274-3281. [CrossRef] [PubMed]

16. Perrault, K.A.; Nizio, K.D.; Forbes, S.L. A comparison of one-dimensional and comprehensive two-dimensional gas chromatography for decomposition odour profiling using inter-year replicate field trials. Chromatographia 2015, 78, 1057-1070. [CrossRef]

17. Stefanuto, P.-H.; Perrault, K.; Stadler, S.; Pesesse, R.; Brokl, M.; Forbes, S.; Focant, J.-F. Reading cadaveric decomposition chemistry with a new pair of glasses. ChemPlusChem 2014, 79, 786-789. [CrossRef]

18. Perrault, K.A.; Stefanuto, P.-H.; Stuart, B.H.; Rai, T.; Focant, J.-F.; Forbes, S.L. Reducing variation in decomposition odour profiling using comprehensive two-dimensional gas chromatography. J. Sep. Sci. 2015, 38, 73-80. [CrossRef] [PubMed]

19. Perrault, K.A.; Rai, T.; Stuart, B.H.; Forbes, S.L. Seasonal comparison of carrion volatiles in decomposition soil using comprehensive two-dimensional gas chromatography-Time of flight mass spectrometry. Anal. Methods 2014, 7, 690-698. [CrossRef]

20. Forbes, S.L.; Troobnikoff, A.N.; Ueland, M.; Nizio, K.D.; Perrault, K.A. Profiling the decomposition odour at the grave surface before and after probing. Forensic Sci. Int. 2016, 259, 193-199. [CrossRef] [PubMed]

21. Sampat, A.; Lopatka, M.; Sjerps, M.; Vivo-truyols, G.; Schoenmakers, P.; van Asten, A. The forensic potential of comprehensive two-dimensional gas chromatography. TrAC Trends Anal. Chem. 2016, 80, 345-363. [CrossRef]

22. Das, M.K.; Bishwal, S.C.; Das, A.; Dabral, D.; Varshney, A.; Badireddy, V.K.; Nanda, R. Investigation of gender-specific exhaled breath volatome in humans by GC × GC-TOF-MS. Anal. Chem. 2014, 86, 1229-1237. [CrossRef] [PubMed]

23. Cordero, C.; Liberto, E.; Bicchi, C.; Rubiolo, P.; Reichenbach, S.E.; Tian, X.; Tao, Q.; Giuria, V.P.; Torino, I. Targeted and non-targeted approaches for complex natural sample profiling by GC $\times$ GC-qMS. J. Chromatogr. Sci. 2010, 48, 251-262. [CrossRef] [PubMed]

24. Tranchida, P.Q.; Donato, P.; Cacciola, F.; Beccaria, M.; Dugo, P.; Mondello, L. Potential of comprehensive chromatography in food analysis. Trends Anal. Chem. 2013, 52, 186-205. [CrossRef]

25. Fullagar, R.; Hayes, E.; Stephenson, B.; Field, J.; Matheson, C.; Stern, N.; Fitzsimmons, K. Evidence for Pleistocene seed grinding at Lake Mungo, south-eastern Australia. Archaeol. Ocean. 2015, 50, 3-19. [CrossRef]

26. Fullagar, R. Residues and usewear. In Archaeology in Practice: A student Guide to Archaeological Analyses; Balme, J., Paterson, A., Eds.; John Wiley \& Sons: New York, NY, USA, 2014; pp. 232-265.

27. Brokl, M.; Bishop, L.; Wright, C.G.; Liu, C.; McAdam, K.; Focant, J.-F. Multivariate analysis of mainstream tobacco smoke particulate phase by headspace solid-phase micro extraction coupled with comprehensive two-dimensional gas chromatography-time-of-flight mass spectrometry. J. Chromatogr. A 2014, 1370, $216-229$. [CrossRef] [PubMed]

28. Stefanuto, P.-H.; Perrault, K.A.; Lloyd, R.M.; Stuart, B.H.; Rai, T.; Forbes, S.L.; Focant, J.-F. Exploring new dimensions in cadaveric decomposition odour analysis. Anal. Method. 2015, 7, 2287-2294. [CrossRef]

29. Armstrong, P.; Nizio, K.D.; Perrault, K.A.; Forbes, S.L. Establishing the volatile profile of pig carcasses as analogues for human decomposition during the early postmortem period. Heliyon 2016, 2, e00070. [CrossRef]

30. Rots, V. Towards an understanding of hafting: the macro- and microscopic evidence. Antiquity 2003, 77, 805-815. [CrossRef] 
31. Barham, L. From Hand to Handle: The First Industrial Revolution; Oxford University Press: Oxford, UK, 2013.

32. Wynn, T. Hafted spears and the archaeology of mind. Proc. Natl. Acad. Sci. 2009, 106, 9544-9545. [CrossRef] [PubMed]

33. Wadley, L. Compound-adhesive manufacture as a behavioral proxy for complex cognition in the middle stone age. Curr. Anthropol. 2010, 51, S111-S119. [CrossRef]

34. Eggert, G. Plastiline: Another unsuspected danger in display causing black spots on bronzes. Verb. der Restaur. zur Erhalt. von Kunst-und Kult. 2006, 2, 112-116.

(C) 2016 by the authors; licensee MDPI, Basel, Switzerland. This article is an open access article distributed under the terms and conditions of the Creative Commons Attribution (CC-BY) license (http:/ / creativecommons.org/licenses/by/4.0/). 